\title{
Does Nothingness presume atemporality? Typical responses in modern European philosophy
}

\author{
Elena Smirnova ${ }^{1, *}$, Dmitry Vorobev $^{1}$, Evgeny Zakablukovskiy $^{1}$ and Alexey Spiridonov ${ }^{1}$ \\ ${ }^{1}$ Minin Nizhny Novgorod State Pedagogical University, Department of Philosophy and Social Science, Bld .1, Ulyanov str., 603005 , \\ Nizhny Novgorod, Russian Federation
}

\begin{abstract}
The article is devoted to Nothingness as a philosophical category. Various thinkers in different times understood it in their own specific way. In the modern age the category became incredibly important and was substantially reconsidered. The question is, can Nothingness have any (imaginary or real) temporal features? The main point of the authors is that exactly in modern European metaphysics 'yes' appeared as an answer to the above query. Nothing got a dynamic nature; it became a base for the Being, namely, the changeable and consequently temporal base. After such notions had shown up, some philosophers and physics responded by trying to find relevant 'proofs' and deny Nothing's existence in the Universe and even Nothingness as a mental construct.
\end{abstract}

\section{Introduction}

What is actually 'Time' and how to interpret it? Such questions have been bothering human minds through the entire history of human race. Ancient Greeks, medieval scholars, modern European scientists tried to unravel the mystery of Time. Even today the basic characteristics of Time are still under discussion. Is Time discrete or continuous? Can it be reversed? Will it end eventually? By answering the question 'what Time is' the thinkers inevitably turned to the question 'what Time is not'. Different answers about the nature of Time's otherness sounded like: 'Eternity', 'Moment', 'Space'. The main goal of the article is to present the concept of Nothingness with reference to Time as found in the philosophical manuscripts and essays. In other words, how did the thinkers of three previous centuries reply to the question 'Can we consider Nothingness as Time's otherness or does it persist in Time just as the entity does?'.

\section{Materials and methods}

We will shortly investigate the question by analyzing the situation in the following branches of philosophy from the 18 th century to the present days:

1. Modern era philosophy.

2. German idealism.

3. Existentialism.

4. Lebensphilosophie.

5. Postmodern philosophy.
6. Philosophy of physics.

NB. In this article we will use the terms 'Nothingness' for significatum and 'Nothing' for designatum. otherness or does it persist in Time just as the entity does?'.

\section{Results}

\subsection{Modern era philosophy}

Nothingness is a philosophical category which is one of the most challenging for discussion. Cambridge dictionary defines the term as a 'state where nothing is present, or where nothing exists that is important or gives meaning to life' [1]. So the main issue with Nothingness is this: how is it possible to talk in terms of existence about something which does not exist? Another question to ask here is: does the absense of Being pre-suppose atemporality?

Probably the first philosopher who made an implicit assumption that Time may exist in Nothing was John Locke. In his Essay Concerning Human Understanding he argued that whatever happens (or does not happen) with Something (or Nothing), Time still continues to exist [2]. But how can Time be 'transferred' directly into Nothingness? The main reason for the atemporality to exist is the absence of change; but if Time exists by itself, then any change, of Something or of Nothing, of Being or of it's negation, is secondary. Therefore, we may conclude that there is Time even if there is no 'is'.

'Why is there something rather than nothing?' - is another version of a question proposed by Gottfried Wilhelm Leibniz in the early 17 th century. Leibniz' argument was about possibility: the possibility for

\footnotetext{
* Corresponding author: elenna-1234@yandex.ru
} 
something to exist is the beginning of its existence. Nothing is easier, simpler than something, according to Leibniz. To overcome this issue, he used God as the ultimate reason. Being is more complicated, thus God is needed for Being to emerge [3].

\subsection{Nothing and Being in Georg Wilhelm Friedrich Hegel's system of philosophy}

G.W.F. Hegel widely used the category of Nothingness when building his philosophical system. Nothing and Being became the basic concepts there, it was actually constructed by elaborating those. His idea was to include both concepts as important parts of the Universe [4]. Hegel used and developed this category mostly in his Science of Logic. F.W.J. von Schelling believed that for Hegel Nothingness was just the negation of Being, but some modern researchers were inclined to think that for Hegel this term meant more than that. For example, Protopopov believes that Hegel understood Nothing as a source of Being and, more generally, of any development [5]. The authors tend to agree with this opinion. Describing it, Hegel asserted the identity and opposition of Being and Nothing at the same time. Moreover, they move into each other. Being equal in that motion, however, they move in different directions. Hegel's Nothing is not just 'pure' nothing but it possesses some pattern inside it from which Being starts and evolves [6]. From this perspective Nothing is rather dynamic than stable, even as dynamic as Being is. We may conclude that Time within Nothing should have the same rights as in Being. In Hegel's system Time within Nothing is not just some duration without any quantity characteristics. Logically continuing to develop his ideas, we may say that Nothing's Time must be absolutely the same as Being's Time.

\subsection{Existentialism about Nothing}

The problem of Nothing was also incredibly important for another philosopher - Martin Heidegger. He considered it a fundamental and the most profound category. For him, Nothing was the condition of everyone's existence. But is there Time in Heidegger's Nothing? [7] For him, Being certainly is, while Time does not exist, but times (as a verb in Present Indefinite). From that point of view, Time flows somewhere between Nothing and Something: it transforms Nothing into Something and vice versa.

For existentialists, Nothingness means experience. It is something that happens, something that a person lives through. J.-P. Sartre proved that Nothingness is constructed inside human mind by an act of denying. From that angle it seems to be out (outside) of Time, but Sartre conferred deep ontological context on Nothing [8]. These two points (brought together) provide Nothing with certain temporal characteristics.

In Heidegger's philosophy the experience of Nothingness does not mean understanding or some type of essential connection, but directly revealing inside one's mind [9]. So, Nothing does exist in Time, but still remains timeless. Heidegger described it as otherness of the Being, but it was 'dynamic' otherness. Nothing becomes a condition for entity. Nothingness is a ground even for denying [7]. And as far it is dynamic/active, it should have some connection with the Time.

Time and Nothing actually have a lot in common. They both do not belong to the world of entity. And that is particularly why we are not able to answer or even ask such questions as 'What is Time?' or 'What is Nothingness?'They both are neither what nor entity and cannot belong to a set of objects which are answers on what-questions [9]. There is one more thing about them: they are not a simple negation of entity, Being neither entity nor not-entity. To sum it up, Heidegger put Nothingness into the heart of metaphysics by replacing Being with it [10].

\subsection{Nothing in the philosophy of Nietzsche and his interpreters}

Nietzschean meaning of Nothingness is however quite different. His interpretation was closer to the one practiced by Buddhists [11]. In his philosophy, Nothing becomes a goal and a purpose. Anyone trying to achieve a specific goal eventually starts feeling disappointed but it will never happen if Nothing is a goal. If the Old Testament (and everyone else who believes in 'ex nihilo' concept) assumes that Nothing is the very beginning, for Nietzsche it is the end, the ultimate goal and the final stage of the Being. Any values become Nothing (null and void) because they cannot 'embrace' the whole world.

Apart from that, the question is: should Nothing be regarded as temporal with all its 'satellite' attributes (e.g. mobility and causality) — as far as any motion or cause presume change and therefore the presence of Time- or should it be viewed as timeless, as something which would exist even after all times? Nietzsche wrote that it is eternal, because the whole life is an 'eternal return' [11], an eternal motion from Nothing to Being and backwards.

The s.c. 'Will to Nothing'(in the history of philosophy) turns into a source of creativity. One of the main topics for Gilles Deleuze, a famous interpreter of Nietzsche, is the language as symbolic order (he is influenced by J. Lacan here). For Deleuze, Nothing is what lies beyond the language. In this context, Nietzschean Will to Nothing is an important notion: it is now regarded as some unconscious power (which bursts from the literary language) and the ultimate goal of art and literature [12]. In order to relieve this power, Deleuzean Nothingness must be dynamic, and contain some pattern which evolves in time.

Jacques Derrida, following the line charted by previous philosophers, considers Nothing as a base for any expressions of Being. Nothing is fundamental for a system, keeping all its parts from falling apart. Nothing is a condition for both the language and philosophy; it creates open space for asking and talking [13]. 


\subsection{Negative theology by Sartre and Kierkegaard}

Another meaning of Nothingness can be found in the writings of Søren Aabye Kierkegaard. The feeling which a human being perceives in front of Nothings is fear. Later, Thomas Altizer interpreted this intuition as the fear of the end of the Christian world. In Kierkegaard's view, one experiences similar emotions of the Eternity. Moreover, when talking of nihilism (which followed Kierkegaard's philosophy of apocalypse) Altizer describes 'apocalyptical version' of Jesus Christ as the one who 'embodies' the end of the mundus creatus, so we may also consider this particular end as Nothing [14]. Nietzsche and Kierkegaard are usually referred to as being in opposition to each other but probably for both of them Nothing is eternal.

The same motives can be found in J.-P. Sartre's understanding of Nothing. Josh Toth thinks that Sartre's interpretation of the term is close to the idea of God. Following Christina Howells, Toth calls this school of thought 'negative theology' [15].We can also name it 'theology of Nothing'. If Nothing is equal to God, what would happen with Time inside it? In Christian tradition (most prominent scholar here is, of course, Boetius) God is often considered as a Being outside of time and space, but also the creator of Time. Many Christians believe that God knows the future, the present and the past as well (though philosophers of religion still debate on the congruence and consequences of such attributes of God as eternity, knowledge, and providence) [16]. But Nothing should be - as we mentioned before - eternal and eternity in this case does not mean 'otherness' of Time, but it does embrace Time the same way as Nothingness embraces Being. It is quite a different interpretation of eternity, contrary to what the Bible says. Eternity is not the negation of Time, but its inner source, something 'bigger' than Time: it includes Time and the possibility for this Time to last.

\subsection{Negative theology by Sartre and Kierkegaard}

The notion that the Universe has evolved from Nothing was popular not only among medieval scholars: at least the young Georges Lemaitre, a renowned 20th century astrophysicist and catholic official, tried to take this concordist stance as well [17]. But the author of the general relativity theory A. Einstein had another view on the topic. A. Lightman pointed out that Einstein was the one who rediscovered Nothing by denying ether [18]. However, the authors believe that to be an exaggeration. It seems to be more relevant that Einstein supposed only Universe (Being) to exist - as his steady-state model of the Universe suggests [19].The category of Time in Einstein's interpretation is under discussion as well. There is even an opinion that Einstein denied Time at all. F. Weinert wrote, proving his points by the famous physicist's quotations, that Einstein viewed Time as not only relative but even not real. By summarizing these points (non-existence of both Time and Nothing) we would refer to Parmenides' thoughts of Being and modern 'deniers of Nothingness' whom we will discuss further.

Few decades before Heidegger put Nothingness into the heart of metaphysics, Henri Bergson had become the one who tried to completely eliminate it from the realm of philosophy. In Creative Evolution he proposed a following thought experiment. If a person stayed for a while in some condition where there was not any outward signal perceived, this condition still cannot be considered Nothing because of that person's presence per se [20]. This argument is very close to R. Descartes' cogito ergo sum, however, while Descartes made a conclusion about the existence, Bergson argues that such thing as Nothing (non-existence) cannot exist even as a self-standing mental construct.

The very idea of Nothingness can be imagined only because of the human ability to remember. One expects to meet something, but it is not there, so the person starts talking about Nothing. It can appear in our mind only when we compare real and imaginary order of things [20]. Bergson was critical of Einstein's theory of relativity and even included his objections into his 'Duration and simultaneity'. By arguing that there is only one real Time because there is only one chosen observer, he stands against both the idea of multiple Times and that of the Time relativity.

However, in Creative Evolution Bergson shows up as a true relativist. Not only the speed of time, but even Being and Nothingness turn out to be dependent on the observer. In the end, he makes the conclusion that Nothing is nothing; it neither really exists, nor underlies any object or phenomenon or any other manifestation of Being. There is only Being which changes its forms, and that is very close to Einstein's steady-state Universe.

\subsection{Contemporary 'deniers of Nothingness'}

Along this line, some contemporary philosophers and scientists try to find new arguments for denying Nothingness. For example P. Van Inwagen argues with Leibniz about the possibility of Nothing. Van Inwagen states that Nothing is not easier than Being because there are so many ways for things to be and only one way not to be. Because of that, it is simpler to be than not to be. It is the reality of Nothing that should be proven, but not the opposite [21]. However, looking at any live creature we clearly understand that there are a lot of ways for it to die and actually no way to be reborn. Or, if we talk about ourselves, our lives, when our existence can possibly finish at any moment (which is quite terrifying), the idea of our dead body to be just another manifestation of Being will not satisfy anyone because our personality will become Nothing. Keeping in mind the above definition of Nothingness, we, human beings, consider the concept of Personality as something meaningful, so the result of such a loss may be interpreted as Nothingness. So it seems that Nothingness, again, depends on the observer.

Some modern authors prefer a more 'scientific' approach to prove their point. Max Tegmark insists that the necessity to be is proven by the universal math of 
natural laws. The consequence of their presence is the physical Universe as we know it, shortly speaking, the Being itself. That is why Nothingness is impossible [22].

In 1973 Edward P. Tyron raised an objection against 'creatio ex nihilo' notion and put it in scientific terms (like Big Bang theory). He starts with the vacuum which we can interpret as nihil. He insisted that vacuum is not quite Nothing but it is filled with so called 'virtual' particles which are real but have a very short life period. So, there is still some energy in vacuum, at the very low level but anyway [22]. Actually, despite the various arguments it doesn't seem that these authors (nothingdeniers) go much further than Parmenides did [23]. For the latter the Time is an illusion because of the Being's stability.

But Parmenides' logic seems to be stronger than one of his modern followers. His schemata can be presented like that:

1. There is only Being, because we can only imagine what is Being and cannot imagine what is Nothing.

2. There cannot be two or more Beings, otherwise they would have to be separated from each other by nonBeing (while non-Being does not exist).

3. If it had parts, then the parts should be delimited from each other by non-Being (which, again, does not exist).

4. If there are no parts and the Being is uniform, then there is neither motion nor multiplicity in the Universe (otherwise, one Being must be moving in relation to the other).

5. Since there is neither motion nor multiplicity and there is only one Being, there is neither appearance nor annihilation since the appearance (or annihilation) implies non-Being.

Along Parmenides' line, we may argue that Time implies change (i.e. motion, emergence or annihilation). Change (of Being) implies the presence of something (that is not Being). Logically, Time implies the existence of Nothing. Denying Nothing brings us to the idea of denying Time itself.

Another interesting attempt to dismiss the concept of Nothingness was made by a group of modern physicists. Talking about Nothingness, V. Stenger, F. Wilzek, L. Krauss presumed it should be immune to any change. Thus, it should be very unstable and as soon as it starts to exist it would disintegrate into Being. However, it looks like that by trying to deny Nothingness the above scholars actually proved it as something that should necessarily precede Being. Moreover, by denying Change and Time in this hypothetical Nothing, they asserted the opposite because it must change into Being. They also claimed that the total energy of universe is zero. Peter Lynds believed that to be an argument for the possibility for the Universe to spontaneously appear from Nothing, so it means that Nothing may exist [22].

Lynds himself also offers an answer to the question 'Why is there something rather than nothing?' His logic is the following:

1. The Universe exists.

2. It can exist if and only if it should exist.

3.If it should exist, its existence is eternal.
4. Because the Universe' existence is eternal there never was such a thing as a beginning, creation from Nothing or Nothing (and never will be) [22].

It stays unclear why the Universe cannot exist if it only may exist: there are no proofs of the Universe' obligatory existence. Why could not it be an obligatory 'state of things' in the past or even now? Anyway, how can we be so sure about the future? The interesting fact is that few years before, the same author, talking of Time in his article Time and Classical and Quantum Mechanics: Indeterminacy vs. Discontinuity stated that 'exactly due to there not being a precise static instant in time underlying a dynamical physical process, and the relative motion of body in relative motion or a physical magnitude not being precisely determined at any time, that motion and variation in physical magnitudes is possible' [24].

\section{Discussion and conclusion}

Before 18th century the philosophical thinking of Nothingness mostly inherited an ancient Greek tradition. Nothingness had no ontological status (i.e. it was not meant to exist) but it was only understood as a mental construct. It was obviously 'kept' outside of Time and the Universe. In three latest centuries the situation has radically changed. The philosophers figured out the increased importance of Nothingness. It transformed from null concept to some meaningful idea. Nothing became the ultimate goal, the path to it and its condition. At some point it became more important than the entity (Being) because it assumed the capacity to 'contain' the Being. Someone looking for the 'Truth of Being' can only find it staring into Nothingness, feeling Nothingness immediately close. Nothingness became experiential, and as an experience it acquired temporal characteristics, becoming something meaningful for humans. It was brought into 'human universe' which exists in Time only, while Time was brought into Nothingness. Such Time can last eternally.

The idea of Time's non-existance can be considered as a reaction to the increased growth of such intuitions. Some philosophers (like H. Bergson and A. Einstein) tried to return its previous 'conceptual' (not real) status to Nothingness. We do believe that it became quite relevant to the subject. However, generally, we see that Nothingness, again, became deprived of its ontological status in the larger philosophers' community..

\section{References}

1. Nothingness. Cambridge dictionary. Retrieved from https://dictionary.cambridge.org/dictionary/english/n othingness

2. B.C. Fraassen, An Introduction to the Philosophy of Time and Space. Retrieved from: https://www.princeton.edu/ fraassen/BvF\%20\%20IPTS.pdf (2013) 
3. G.W.F. Leibnitz, Philosophical essays. Edited and translated by R. Ariew and D. Garber. Hackett Publishing Company (1989)

4. J. E. Maybee, - Stanford Encyclopedia of Philosophy. Hegel's dyslecticsRetrieved from: https://plato.stanford.edu/entries/hegel-dialectics/ (2016)

5. I.A. Protopopov, EINAI: The Problems of Philosophy and Theology" The concept of Nothing and the principle of negativity in Hegel's Logic. 3. Retrieved from: https://einai.ru/2014-03Protopopov-2.html. (2014)

6. G.W.F. Hegel, The Science of Logic. (2010)

7. E. Iwuagwu, JIH, Martin Heidegger and the Question of Being, 8, 1 (2017)

8. S.S. Horuzhy, IPH digital library. Nothingness Retrieved from: https://iphlib.ru/library/collection/newphilenc/docu ment/HASHd078491e9cc1c03074c0d0.

9. M. Heidegger, What is Metaphysics? Translated by M. Groth. Retrieved from: https://wagner.edu/psychology/files/2013/01/Heideg ger-What-Is-Metaphysics-Translation-GROTH.pdf (1929)

10. L.B. Wren, Master's Thesis. The Meaning of Nothingness in the Early Philosophy of Martin Heidegger. Retrieved from: https://ecommons.luc.edu/cgi/viewcontent.cgi?articl $\mathrm{e}=3047 \&$ context $=$ luc_theses (1965)

11. F. Nietzsche, The Will to Power. Translated by W. Kaufmann and R. J. Hollingdale. Edited by W. Kaufmann. Vintage Books New York. (1968)

12. C. Erdem, Artaud, Deleuze and the Will to Nothingness. Retrieved from: https://cengizerdem.wordpress.com/2010/05/26/arta ud-deleuze-and-the-will-to-nothingness/ (2010)

13. C. Johnson, System and Writing in the Philosophy of Jacques Derrida. Retrieved from: https://epdf.pub/system-and-writing-in-thephilosophy-of-jacques-derrida-cambridge-studiesin-fre.html (1993)

14. T.J.J. Altizer, Problems of philosophy Russia and Apocalypse. № 7. (1996)
15. J.A. Toth, Différance of Nothingness. Sartre, Derrida and the Problem of Negative Philosophy. Sartre Studies International, 3, doi 0.3167/ssi.2007.130103 (2007)

16. M.J. Murray, M.C. Rea, An Introduction to the Philosophy of Religion. (2008)

17. J-F. Stoffel, (ed.). Msgr. Georges Lemaître, a scholar and a believer: proceedings of a seminar organized at his 100th anniversary (Lovain-laNeuve, November 4, 1994); followed by: La physique d'Einstein (unpublished text by Georges Lemaître, edited by Stoffel, J-F.). Louvain-laNeuve: Centre interfacultaire d'étude en histoire des sciences (1996)

18. A. Lightman, My Own Personal Nothingness: From a childhood hallucination to the halls of theoretical physics. Retrieved from: http://nautil.us/issue/16/nothingness/my-ownpersonal-nothingness. (2014)

19. C. O'Raifeartaigh, B. McCann, W. Nahm, S. Mitton, A steady-state model of the universe by Albert Einstein. Retrieved from: https://www.researchgate.net/publication/26002222 8_A_steadystate_model_of the_universe_by_Albert_Einstein. (2014)

20. H. Bergson, Creative Evolution. Translated by A. Mitchel. (1922)

21. P.V. Inwagen, Proceedings of the Aristotelian Society, Why Is There Anything at All? 70, 95-110. (1996)

22. P. Lynds, Why there is something rather than nothing The finite, infinite and eternal. Retrieved from: https://arxiv.org/abs/1205.2720. (2012)

23. The fragments of Parmenides. Translated into English Hexameters, with Introduction and Notes, by T. Davidson. The Journal of Speculative Philosophy, 2. Retrieved from: https://archive.org/details/fragmentsofparme00parm (1862).

24. P. Lynds, Time and Classical and Quantum Mechanics: Indeterminacy vs. Discontinuity. Retrieved from: https://arxiv.org/abs/physics/0310055. (2003) 